\title{
DETERMINATION OF FLOW RATE CHARACTERISTICS FOR PNEUMATIC VALVES
}

\section{Zdeněk VARGA, Petri KESKI-HONKOLA*}

\begin{abstract}
The standard ISO 6358 is often used for describing flow rate of pneumatic valves. This standard uses sonic conductance and the critical pressure ratio to calculate mentioned flow rate. Different valves can be compared by these two parameters and an accurate mathematical model of flow rate can be created for an actual valve. The presented work is based on the measurements of the charge and the discharge of a tank through a valve. Downstream pressure, upstream pressure, temperature for both supply air and pressurized air inside the tank are monitored. The sonic conductance and the critical pressure ratio are obtained from this process as inverse models for two valves.
\end{abstract}

\section{INTRODUCTION}

For this research of pneumatic valves flow rate characteristics a standard proportional pressure regulator VPPM-6L-L-1-G18-0L10H-A4P-S1C1 was selected. Same valve is used another research work of the authors involving an artificial pneumatic muscle. The vale supplied pressurized air to the muscle and the contraction of the muscle depends on the amount of the pressurized air. For creating a mathematical model of the whole system it is important to describe flow rate through the valve, which was the reason for formulation of the flow rate characteristic for our valve.

In this case flow rate through the valve is described by the sonic conductance $C$ and the critical pressure ratio $b$. This description of flow rate through the screening is taken from the ISO standard 6358 and for mathematical model of the pneumatic valve these two constants must be determined. First attempt to determine these two constants was made by measuring flow rate through the valve while increasing upstream pressure. The first measurement showed that precision was lost by the influence of special measuring equipment.

An alternative method of measuring flow rate characteristics is described in this paper and is referred as second method. The second method is based on the charge and the discharge of a tank through the valve while downstream pressure, upstream pressure, temperature for supply air and for pressurized air inside the tank is monitored. In this paper the second method is applied for determination the sonic conductance and the critical pressure ratio. Determination of the flow rate characteristic is done to two types of valve; VPPM-6L-L1-G18-0L6H-V1P-S1C1 and VPPM-6L-L-1-G18-0L10H-A4P-S1C1 for reasons of comparing the valves and verification of the applied method.

\footnotetext{
- Ing. Zdeněk VARGA, Technical University of Liberec, Department of Applied Cybernetics, Sudentská 2, 46117 Liberec, Czech Republic, zdenek.varga@gmail.com; M.Sc. Petri KeskiHONKOLA, Aalto University, Engineering design and Production, P.O.Box 14400, 00076 Espoo, Finland, petri.keski-honkola@tkk.fi
}

This is an Open Access article distributed under the terms of the Creative Commons Attribution License 2.0, which permits unrestricted use, distribution, and reproduction in any medium, provided the original work is properly cited. 


\section{METHODS}

In the introduction of this paper two methods to determinate flow rate characteristic were mentioned. The first of the methods is based on increasing upstream pressure while the pressurized air goes through a mass flow sensor. This method is explained in detail in the standard ISO 6358. Next two equations which describe the flow rate through the orifices can be found in this standard ISO 6358 [1].

$$
\begin{array}{llll}
q_{m}^{*}=C p_{1} \rho_{0} \sqrt{\frac{T_{0}}{T_{1}}} & \text { for } & \frac{p_{2}}{p_{1}} \leq b & \text { choked flow } \\
q_{m}=C p_{1} \rho_{0} \sqrt{\frac{T_{0}}{T_{1}}} \sqrt{1-\left(\frac{\frac{p_{2}}{p_{1}}-b}{1-b}\right)^{2}} & \text { for } \quad \frac{p_{2}}{p_{1}}>b & \text { subsonic flow }
\end{array}
$$

Custom equipment was manufactured for measuring the flow rate characteristics based on "increasing the upstream pressure". Part of the valve holding the valve nozzle was replaced with the special equipment. With this setup it was possible to set the nozzle to a required fixed position. Without modifications this could not be done.

Figure 1 a) shows the measuring station which was used for measurement and figure 1 b) shows the curvature of dependence flow rate on the upstream pressure. This method has been applied only on valve VPPM-6L-L1-G18-0L6H-V1P-S1C1 because preparing special equipment for holding the nozzle in a constant position is very expensive and work intensive.

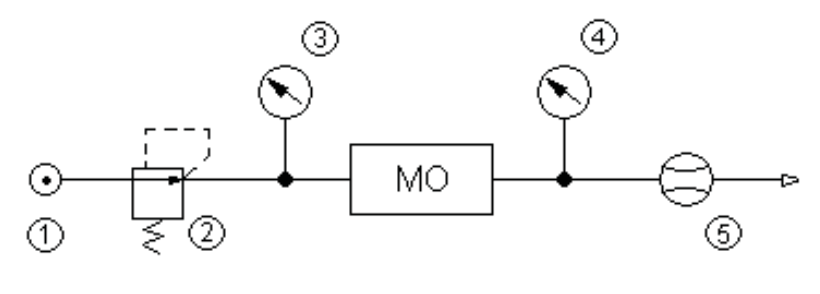

a)

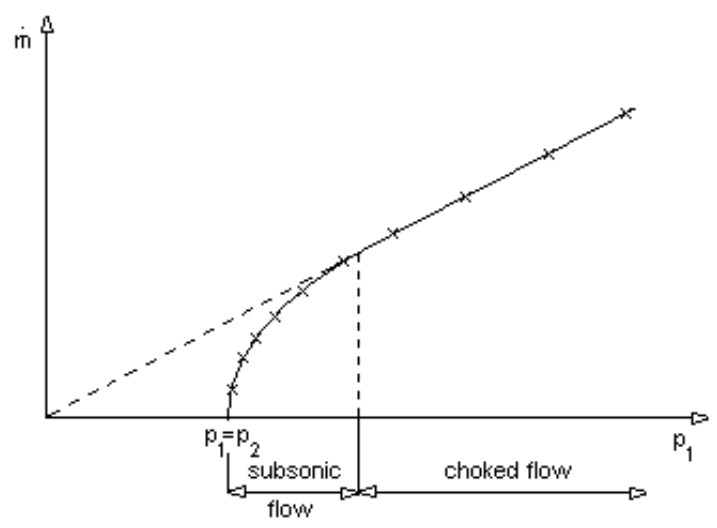

b)

Figure 1: Measuring flow rate characteristic by increasing upstream pressure a)schematic of measuring station ( 1 - pressurized air source, 2 - pressure regulator, 3 pressure sensor ,4 - pressure sensor, 5 - flow meter) b) Dependence flow rate on the upstream pressure 
The second method is based on the charge and the discharge of a tank. In this method an isothermal process is assumed when the state equation of ideal gases (3) is used.

$$
p v=m r T
$$

Equation (3) is used together with equations (1) and (2). Equations (4) and (5) can be obtained from these and they express a derivative of pressure continuance $p_{2}$ in the tank. These equations were used for creating simulation model of charge and discharge of a tank.

$$
\begin{array}{llll}
\dot{p}_{2}^{*}=\frac{\kappa r T_{1}}{V_{2}} C p_{1} \rho_{0} \sqrt{\frac{T_{0}}{T_{1}}} & \text { for } \quad \frac{p_{2}}{p_{1}} \leq b & \text { choked flow } \\
\dot{p}_{2}=\frac{\kappa r T_{1}}{V_{2}} C p_{1} \rho_{0} \sqrt{\frac{T_{0}}{T_{1}}} \sqrt{1-\left(\frac{\frac{p_{2}}{p_{1}}-b}{1-b}\right)^{2}} \text { for } \quad \frac{p_{2}}{p_{1}}>b & \text { subsonic flow }
\end{array}
$$

Picture of measuring tank and schematic of measuring equipment used in the experiment implementing the second method can be seen in Figure 2 a) and b).

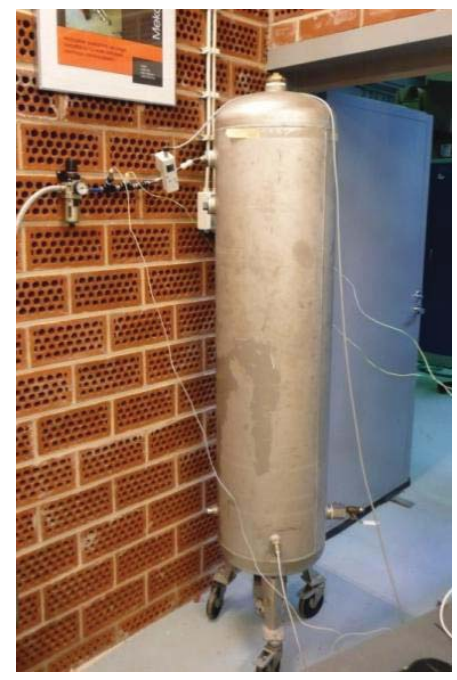

a)

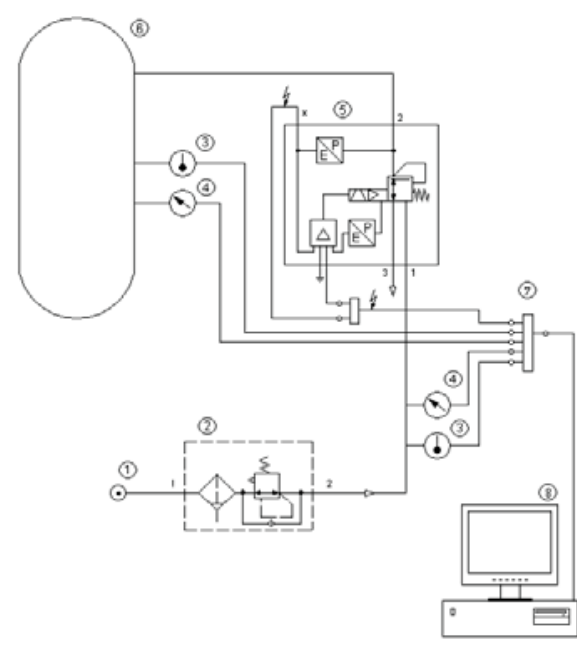

b)

Figure 2: Measuring flow rate characteristic by charge and discharge of a tank a) The measuring tank b) Measuring schematic (1 -Central compressed air supply, 2 - Filter regulator with backflow function AW30K-F03, 3 - Temperature sensor, 4 - Pressure sensor, 5 - Proportional pneumatic valve VPPM, 6 - Pressure tank, 7 - Data acquisition card, 8 - Computer) 
For creating a simulation of charge and discharge of a tank, MATLAB ${ }^{\circledR}$ Simulink was used. It makes possible to compare a lot of measured data with mathematical models, which was a great contribution to the work. Measurements made with the two valves were compared to theoretical values.

Figure 3 and Figure 4 show two Simulink models created to determine sonic conductance $C$ and the critical pressure ratio $b$ from the measured data. This procedure is described in the next chapter.

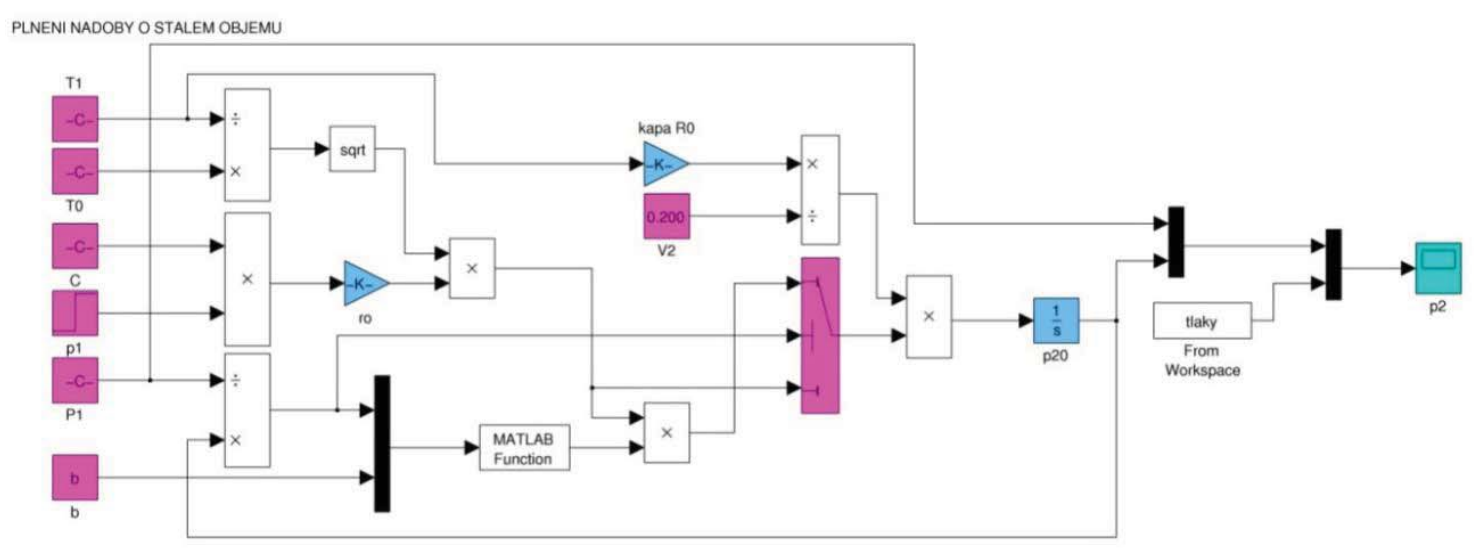

Figure 3: Simulation schematic of a tank charge in Simulink

ODVETRANI NADOBY O STALEM OBJEMU

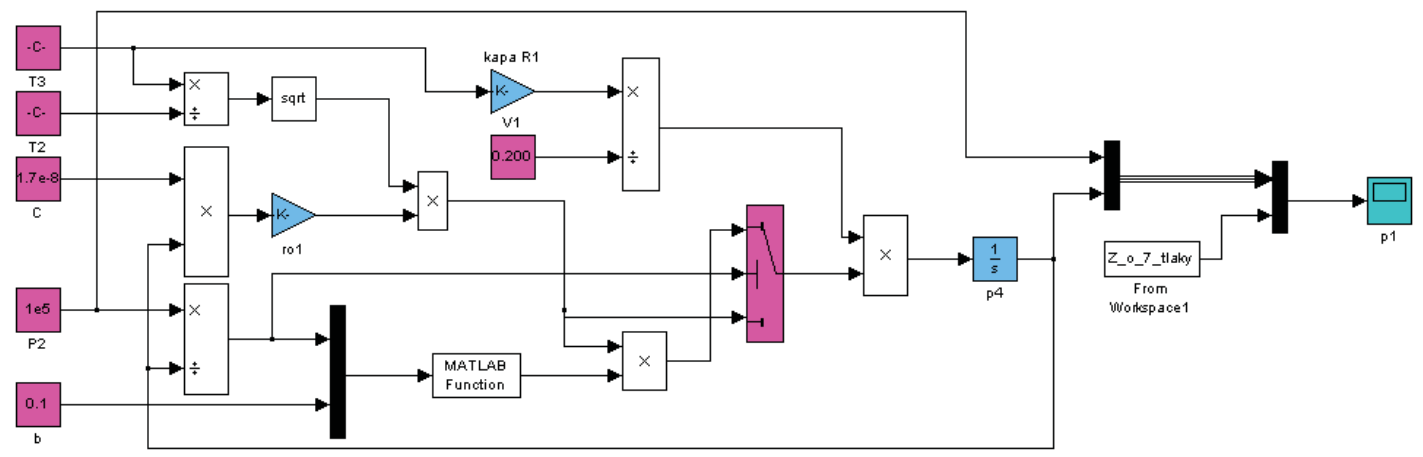

Figure 4: Simulation schematic of a tank discharge in Simulink 


\section{RESULTS}

Two types of measurements were made, firstly, the flow rate characteristic was measured by increasing upstream pressure as depicted in Figure 1 and secondly, flow rate characteristic was measured by charge and dischrge of a tank as shown in Figure 2 . The results from the first method are shown in Figure 5. Measured data are represented as blue circles. Green curvature represents theoretical approximation obtained as a numerical solution searching sonic conductance $C$ and the critical pressure ratio $b$.

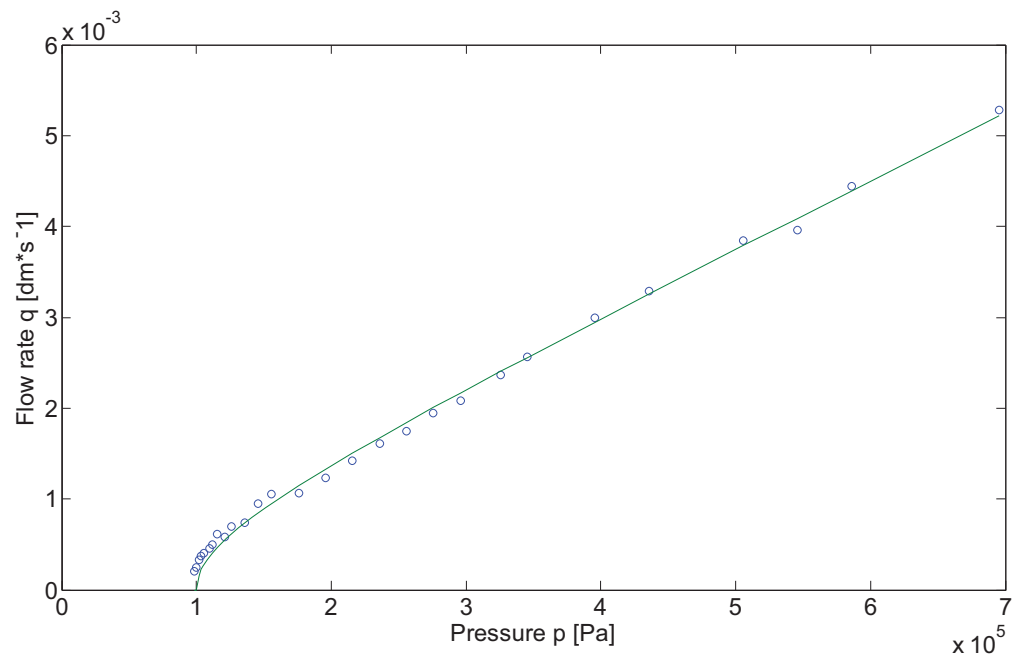

Figure 5: Dependence of flow rate to the upstream pressure - data from the first method measurement

For numerical approximation of the measured data a special program was created in MATLAB ${ }^{\circledR}$ this program used function fminsearch from the MATLAB ${ }^{\circledR}$ toolbox. The function fminsearch finds the minimum of a function, in our case function (2) which describes the flow rate through the orifices for event subsonic flow.

The results from first methods:

$$
\begin{gathered}
C=6,329 \mathrm{e}-09\left[\mathrm{~m}^{\wedge} 3 /\left(\mathrm{s}^{*} \mathrm{~Pa}\right)\right] \\
b=0,1527[-]
\end{gathered}
$$

As mentioned before this method has been applied only on valve VPPM-6L-L1-G18-0L6HV1P-S1C1 because preparatio of the special equipment for holding the nozzle in constant position is very expensive and work intensive. 
The second method of determining the flow rate characteristic uses the results obtained from the charge and discharge of the tank. In fact this second method is used to describe the flow rate (constant of sonic conductance $C$ and the critical pressure ratio $b$ )through the valve in the case when the valve is attached to supply pressure and in the second case, to ambient pressure. The data from the measurements of charging the tank through the valve VPPM-6L-L-1-G18-0L10H-A4P-S1C1 are shown in Figure 6, the same curvature was obtained for the valve VPPM-6L-L1-G18-0L6H-V1P-S1C1with first method

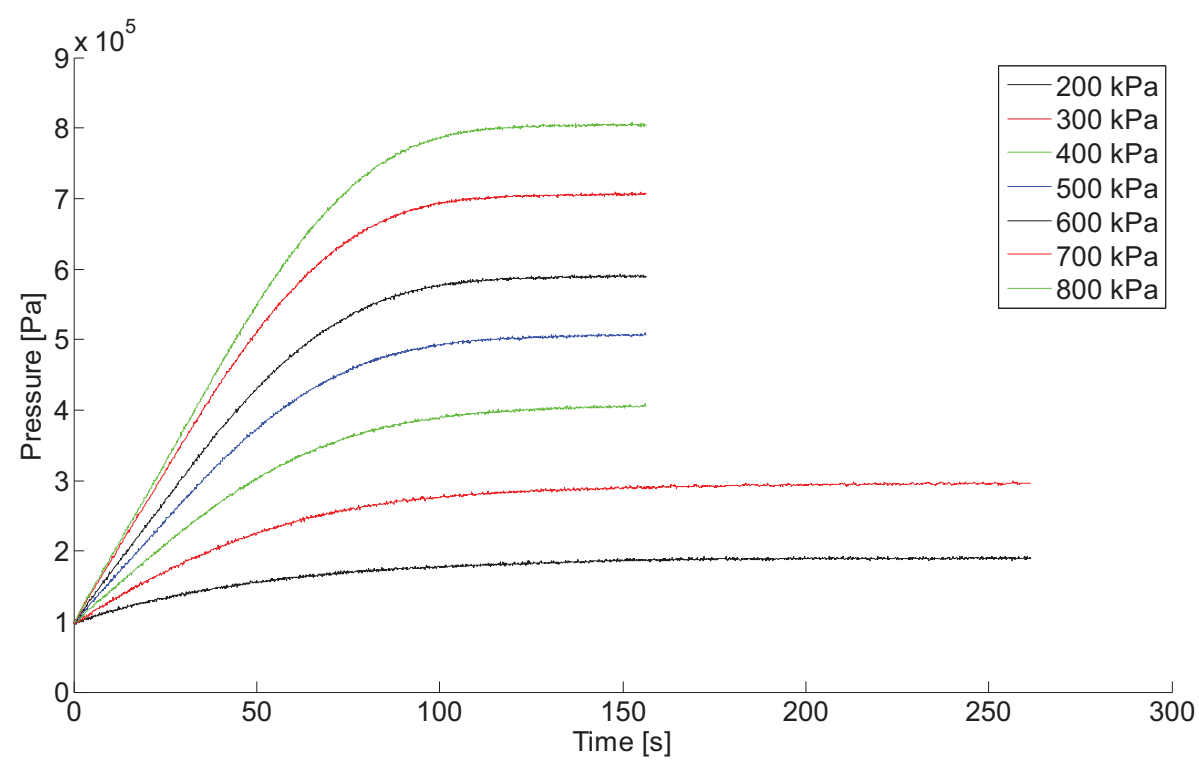

Figure 6: Graph of pressure in a tank on time - data from the measuring charge a tank

The data from the measurement was smoothed by applying the Savitzky-Golay filter and compared to the theoretical model which is shown in Figure 3.

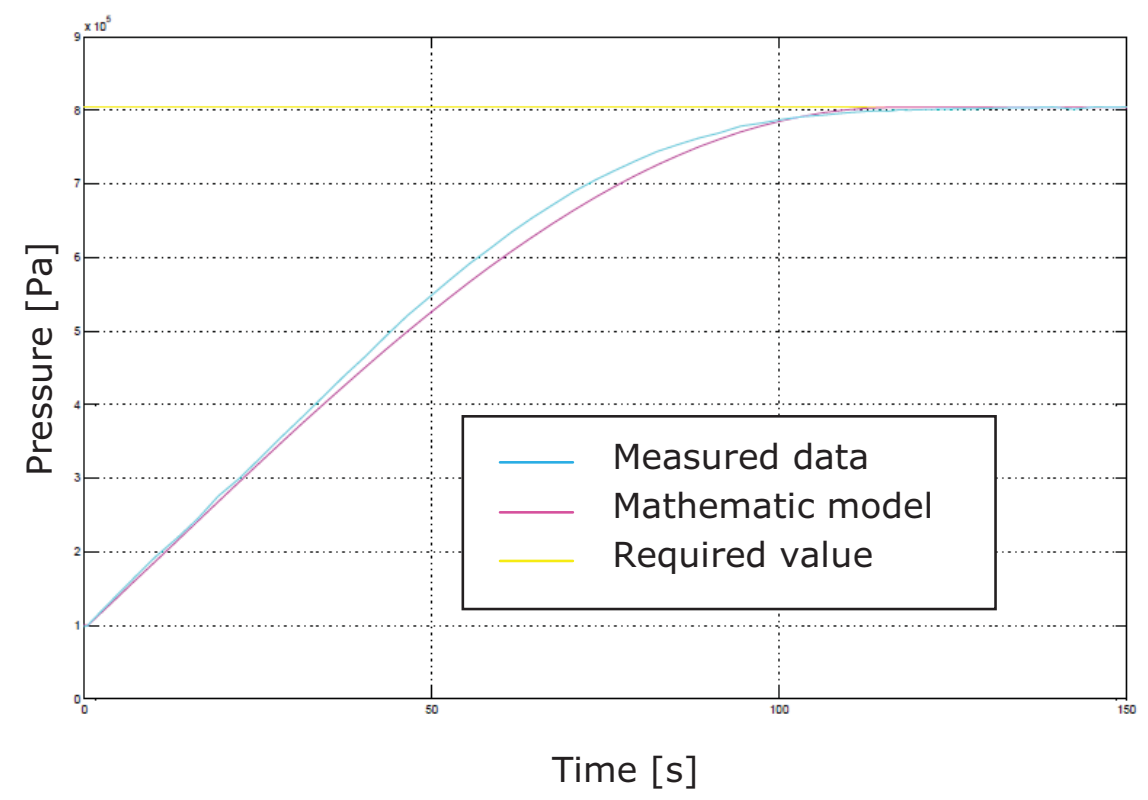

Figure 7: Graph of pressure in a tank on time - results from the simulation of charge a tank in Simulink 
The comparison of measured data and simulation is shown in Figure 7 for the final value of pressure inside a tank 8kPa - valve VPPM-6L-L-1-G18-0L10H-A4P-S1C1.

Values of critical pressure ratio $b$ for each final pressure in the tank were determined based on knowledge that the linear part of the curvature of the charge is describe by equation (1) and the behaviors of flow rate in the second part of the curvature is described by equation (2). Of note is that the critical pressure ratio $b$ expresses the divide of the downstream and the upstream pressure which flow becomes choked [1].

For determination of the critical pressure ratio a derivative of smoothed measured data was made, and the point where the derivative exchanges determines the mentioned critical pressure ratio. The values of sonic conductance $C$ were determined from the equation which describes the flow rate through the orifices for subsonic flow. The results of critical pressure ratio and sonic conductance for different values of upstream pressure are shown in Table 1 and 2 .

Table 1: The values of critical pressure ratio and sonic conductance determined from the charge of a tank - valve VPPM-6L-L-1-G18-0L10H-A4P-S1C1

\begin{tabular}{|c|c|c|}
\hline $\begin{array}{c}\text { Upstream pressure } \\
p_{1}[\mathrm{kPa}]\end{array}$ & $\begin{array}{c}\text { critical pressure ratio } \\
b[-]\end{array}$ & $\begin{array}{c}\text { sonic conductance } \\
C\left[\mathrm{~m}^{\wedge} 3 /\left(\mathrm{s}^{*} \mathrm{~Pa}\right)\right]\end{array}$ \\
\hline 200 & 0,56 & $0,90 \mathrm{e}-8$ \\
\hline 300 & 0,41 & $1,30 \mathrm{e}-8$ \\
\hline 400 & 0,36 & $1,55 \mathrm{e}-8$ \\
\hline 500 & 0,40 & $1,62 \mathrm{e}-8$ \\
\hline 600 & 0,44 & $1,65 \mathrm{e}-8$ \\
\hline 700 & 0,45 & $1,65 \mathrm{e}-8$ \\
\hline 800 & 0,46 & $1,62 \mathrm{e}-8$ \\
\hline
\end{tabular}

Table 2: The values of critical pressure ratio and sonic conductance determined from the charge of a tank - valve VPPM-6L-L1-G18-0L6H-V1P-S1C1

\begin{tabular}{|c|c|c|}
\hline $\begin{array}{c}\text { Upstream pressure } \\
p_{1}[\mathrm{kPa}]\end{array}$ & $\begin{array}{c}\text { critical pressure ratio } \\
b[-]\end{array}$ & $\begin{array}{c}\text { sonic conductance } \\
C\left[\mathrm{~m}^{\wedge} 3 /\left(\mathrm{s}^{*} \mathrm{~Pa}\right)\right]\end{array}$ \\
\hline 200 & 0,56 & $1,08 \mathrm{e}-8$ \\
\hline 300 & 0,41 & $1,43 \mathrm{e}-8$ \\
\hline 400 & 0,35 & $1,61 \mathrm{e}-8$ \\
\hline 500 & 0,37 & $1,68 \mathrm{e}-8$ \\
\hline 600 & 0,38 & $1,72 \mathrm{e}-8$ \\
\hline 700 & 0,33 & $1,73 \mathrm{e}-8$ \\
\hline
\end{tabular}


A part of the second method of determination, a constant describing the flow rate through the valve is discharge of a tank. In this method we used a different method of determination for constant $C$ and $b$, in the first step we provided the measurements of the discharge of a tank and we made a visualization of measured data on the graph see Figure 8 .

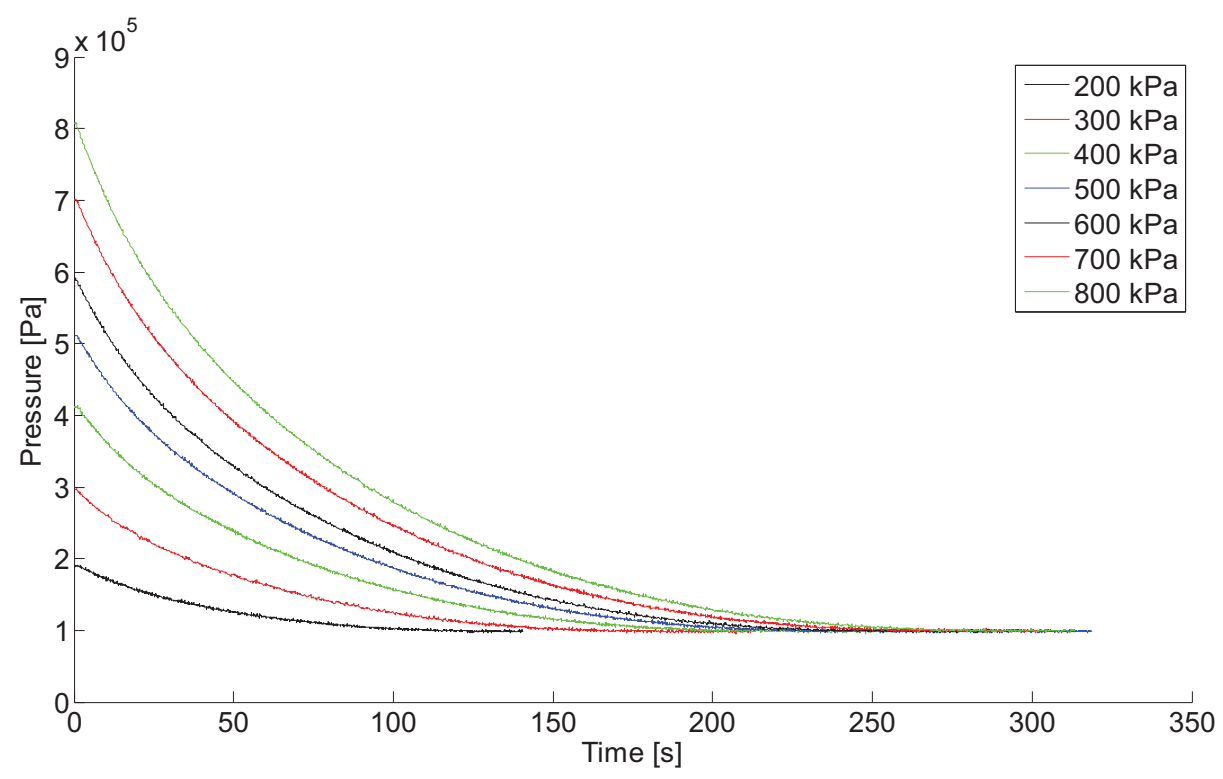

Figure 8: Graph of pressure in a tank on time - data from the measured discharge a tank

As in the charge of a tank the Savitzky-Golay filter was applied for smoothing the measured data and determination of constants $C$ and $b$ can be made.

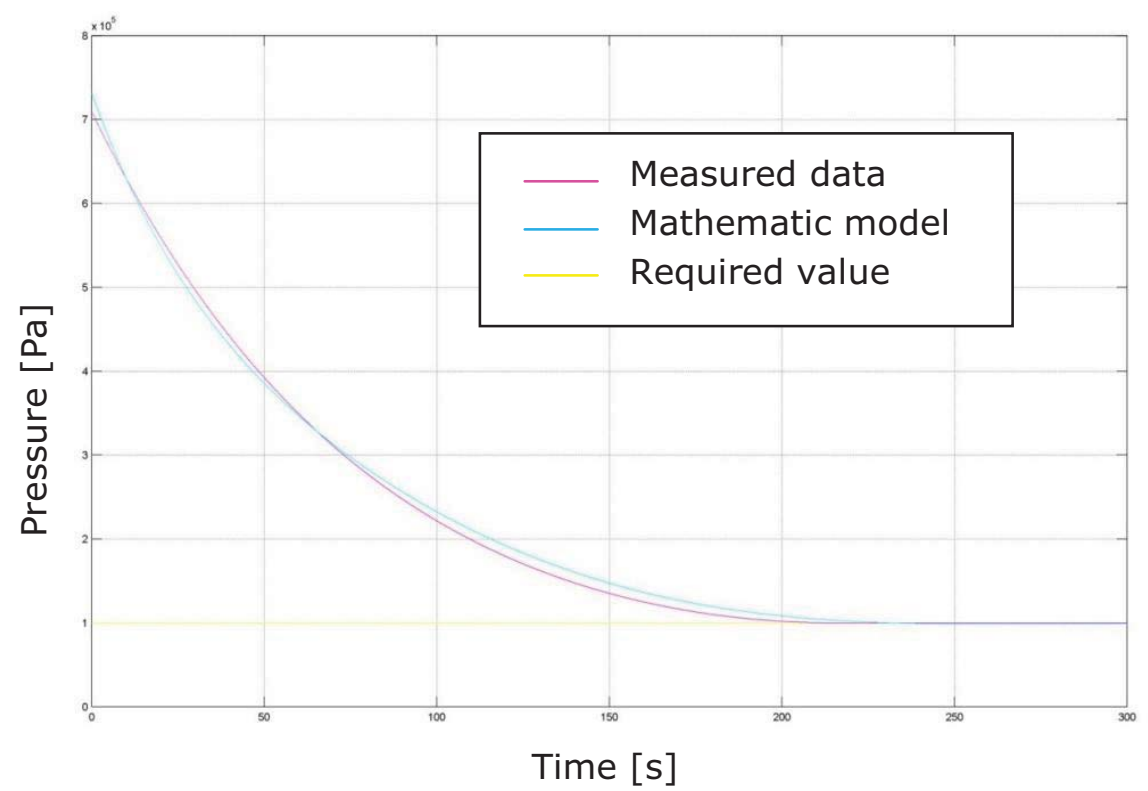

Figure 9: Graph of pressure in a tank on time - results from the simulation of discharge a tank in Simulink 
For evaluation of the constant was used a combination of the simulation of a tank discharge made in Simulink (see Figure 4 ) and a special program in MATLAB ${ }^{\circledR}$ were used. This special program uses an fminsearch function for searching the mentioned constants. The method of discharge of a tank was used for charting of the silencer influence on the flow rate characteristic (see Table 3 to 5).

Table 3: The values of critical pressure ratio and sonic conductance determined from the discharge of a tank - valve VPPM-6L-L-1-G18-0L10H-A4P-S1C1 without silencer

\begin{tabular}{|c|c|}
\hline $\begin{array}{c}\text { critical pressure ratio } \\
b[-]\end{array}$ & $\begin{array}{c}\text { sonic conductance } \\
C\left[\mathrm{~m}^{\wedge} 3 /\left(\mathrm{s}^{*} \mathrm{~Pa}\right)\right]\end{array}$ \\
\hline 0,1178 & $1,7150 \mathrm{e}-8$ \\
\hline
\end{tabular}

Table 4: The values of critical pressure ratio and sonic conductance determine from the discharge of a tank - valve VPPM-6L-L-1-G18-0L10H-A4P-S1C1 with silencer

\begin{tabular}{|c|c|}
\hline $\begin{array}{c}\text { critical pressure ratio } \\
b[-]\end{array}$ & $\begin{array}{c}\text { sonic conductance } \\
C\left[\mathrm{~m}^{\wedge} 3 /\left(\mathrm{s}^{*} \mathrm{~Pa}\right)\right]\end{array}$ \\
\hline 0,1017 & $1,5608 \mathrm{e}-8$ \\
\hline
\end{tabular}

Table 5: The values of critical pressure ratio and sonic conductance determine from the discharge of a tank - valve VPPM-6L-L1-G18-0L6H-V1P-S1C1 without silencer

\begin{tabular}{|c|c|}
\hline $\begin{array}{c}\text { critical pressure ratio } \\
b[-]\end{array}$ & $\begin{array}{c}\text { sonic conductance } \\
C\left[\mathrm{~m}^{\wedge} 3 /\left(\mathrm{s}^{*} \mathrm{~Pa}\right)\right]\end{array}$ \\
\hline 0,1153 & $1,5873 \mathrm{e}-8$ \\
\hline
\end{tabular}




\section{Discussion}

Results from the first and second methods were verified with mathematic models of charge and discharge of a tank in Simulink. When results from the second method are used (see Figures 7 and 9) satisfactory results are obtained. The curvature of the measured data has a very similar shape to the curvature from the mathematic model. Nevertheless, when comparing the results from the first method, which was applied only on valve VPPM-6L-L1-G18-0L6H-V1P-S1C1, we can see a very different value of sonic conductance can be seen, around one decimal place. The pressure ratio is even more different but sonic conductance $b$ from the first method is close to the $b$ from the second method.

Differences between the first and second methods are believed to be caused by the special equipment for holding the nozzle in a fixed position. If the results from the first method are used to obtain the mathematic model of charge or discharge, results are very unsatisfactory.

In the results chapter the determination of the flow rate characteristic from the measurements was shown with different upstream pressures by charging and discharging the tank. The first method gives us only results for one flow rate, from supply pressure to applied load. In the real application pressurized air comes from a central compressed air supply and the applied load is an artificial pneumatic muscle. The second method gives better overview of behavior of flow rate for both ways in contrast to the first method. During the process of determination of the constants $C$ and $b$ the problem of how to find a derivative while using the second method must be solved. Using the second method to automatically build the mathematic model in MATLAB ${ }^{\circledR}$ still needs work, but in this case it main purpose was to help with verification of results.

During the measurements the influence of the silencer/ on flow rate during discharge of the tank was tested. Due to this experiment it can be understood how the behavior of the pneumatic circuit during the process of discharge can be biased. The results from this experiment is noted in Table 3 and 4 and from knowledge gained from measurements and simulations it can be said that the highest value of constant $C$ is very important for the time of discharge and the shape of curvature in the case of discharge.

In this paper when it is mentioned that second method provides satisfactory results it is based on literature research of similar test results. This research uncovered a very important annotation about the value of constant $b$. In the rough estimation of the parameter $b$ (e.g. 0,4 instead of 0,2 ) results in the error in the valves yields $14 \%$ of flow rate rate [5]. 


\section{Conclusion}

The goal of this work was to find a method that would allow us to describe the flow rate through the valve. For this method a standard from the ISO 6358 was chosen. Method of increasing upstream pressure which is named in the first method in this paper was applied. This method is explained in the standard ISO 6358. Construction of the valve was a disadvantage for the application of this method for measuring flow rate characteristic on the valve in both ways of flow, from supply to applied load and from applied load to the outlet.

The main contribution of this paper is application of the second method where a tank is charged and discharge. With this method we were able to determine the constants that allow the description of flow rate both ways. Process of determining the constant from the charge of a tank is simpler than from the discharge of a tank. Additionally, continued testing of the second method is easier due to the lack of special equipment for holding a nozzle in fixed position needed in the first method.

Nevertheless, for the mathematic model of valve it is still required to determine the $C$ and $b$ as a function of valve nozzle position. The functions which will be designed from measurements presented in this paper will help in identifying the flow rate in the whole range of movement of the nozzle which is necessary for mathematical model needed in pneumatic muscle research. The aim of this paper was only to present how the measurements were made but the results build a foundation for the future work with construction of functions $C$ and $b$ and their dependence on the nozzle position.

\section{ACKNOWLEDGMENTS}

The work presented in this paper was supported by the Students Grant Project Control of Fluid Servosystems in Technical University of Liberec and we would like to thank the Aalto University - Finland for measurements of flow rate characteristic with the tank.

\section{NOMENCLATURE}

$b \quad$ critical pressure ratio

C Sonic conductance

$p_{1} \quad$ Absolute upstream pressure

$p_{2} \quad$ Absolute downstream pressure

$q_{\mathrm{m}} \quad$ Mass flow

$r \quad$ Gas constant

$\mathrm{T}_{0} \quad$ Temperature - standard reference condition

$\mathrm{T}_{1} \quad$ Temperature - upstream condition

$V \quad$ Volume of chamber

$\rho_{0} \quad$ Air density
$[-]$

$\left[\mathrm{m}^{3} /(\mathrm{s} . \mathrm{Pa})\right]$

$[\mathrm{Pa}]$

$[\mathrm{Pa}]$

$[\mathrm{kg} / \mathrm{s}]$

$[\mathrm{J} /(\mathrm{kg} . \mathrm{K})]$

$[\mathrm{K}]$

$[\mathrm{K}]$

$\left[\mathrm{m}^{5}\right]$

$\left[\mathrm{kg} / \mathrm{m}^{3}\right]$ 


\section{REFERENCES}

[1] ISO 6358: Pneumatic fluid power - Components using compressible fluids Determination of flow-rate characteristics, 1989

[2] Kawashima K., Ishii Y., Funaki T., Kagawa T.: Determination of Flow Rate Characteristics of Pneumatic Solenoid Valves Using an Isothermal Chamber, Journal of Fluids Engineering, March 2004, Vol. 126, 273-279, DOI: $10.1115 / 1.1667888$

[3] Giorgi d. R., Kobbi N., Sesmat S., Bideauxthermal E.: Model of a Tank for Simulation and Mass Flow Rate Characterization Purposes, Toyama, Proceedings of the 7th JFPS International Symposium on Fluid Power, September 15-18 2008, pp.225-230.

[4] Giorgi d. R., Bideaux E., Sesmat S.: Using Inverse Model for Determining Orifice Mass Flow Rate Characteristics. Tsukuba, Proceedings of the 6th JFPS International Symposium on Fluid Power, November 7-10 2005, pp.380-385.

[5] Nevrlý J.: Introduction to the modeling pneumatic systems (Original Czech title - Úvod do modelování pneumatických systémů), Česká strojnická společnost, Ústřední odborná sekce Hydraulika a pneumatika, Praha, 2003,1. Vydání náklad 40 výtisků, pp. 79, ISBN 80-02-01549-5 